\title{
Multilevel tracking power supply for switch-mode audio power amplifiers
}

Iversen, Niels Elkjær; Lazarevic, Vladan; Vasic, Miroslav; Knott, Arnold; Andersen, Michael A. E.; Cobos, Jose A.

Published in:

Proceedings of APEC 2018

Link to article, DOI:

10.1109/APEC.2018.8341043

Publication date:

2018

Document Version

Peer reviewed version

Link back to DTU Orbit

Citation (APA):

Iversen, N. E., Lazarevic, V., Vasic, M., Knott, A., Andersen, M. A. E., \& Cobos, J. A. (2018). Multilevel tracking power supply for switch-mode audio power amplifiers. In Proceedings of APEC 2018 (pp. 406-411). IEEE. https://doi.org/10.1109/APEC.2018.8341043

\section{General rights}

Copyright and moral rights for the publications made accessible in the public portal are retained by the authors and/or other copyright owners and it is a condition of accessing publications that users recognise and abide by the legal requirements associated with these rights.

- Users may download and print one copy of any publication from the public portal for the purpose of private study or research.

- You may not further distribute the material or use it for any profit-making activity or commercial gain

- You may freely distribute the URL identifying the publication in the public portal

If you believe that this document breaches copyright please contact us providing details, and we will remove access to the work immediately and investigate your claim 


\title{
Multilevel tracking power supply for switch-mode audio power amplifiers
}

\author{
Niels E. Iversen ${ }^{1}$, Vladan Lazarevic ${ }^{2}$, Miroslav Vasic ${ }^{2}$, Arnold Knott ${ }^{1}$, Michael A.E. Andersen ${ }^{1}$ and Jose A. Cobos ${ }^{2}$ \\ ${ }^{1}$ Technical University of Denmark, Department of Electrical Engineering, 2800, Kgs. Lyngby, Denmark. \\ ${ }^{2}$ Universidad Politecnica de Madrid, Centro de Electronica Industrial - CEI, Madrid, Spain. \\ Email: neiv@elektro.dtu.dk
}

\begin{abstract}
Switch-mode technology is the common choice for high efficiency audio power amplifiers. The dynamic nature of real audio reduces efficiency as less continuous output power can be achieved. Based on methods used for RF amplifiers this paper proposes to employ envelope tracking techniques to the power supply in order to improve efficiency. A $100 \mathrm{~W}$ prototype system was designed. Measured results show that systems employing envelope tracking can improve system efficiency from $2 \%$ to $12 \%$, i.e. a factor of 6 . The temperature rise is strongly reduced, especially for the switching power MOSFETs where it is halved from $100{ }^{\circ} \mathrm{C}$ to $50{ }^{\circ} \mathrm{C}$.
\end{abstract}

\section{INTRODUCTION}

Switch-mode power audio amplifiers, also know as classD amplifiers, have become the conventional choice for audio amplifications as they have excellent audio performance with very low distortion [1]-[3] and superior efficiency compared to linear amplifiers such as class-A and class-AB [4]. However the measurement technique for measuring the efficiency normally utilizes sine waves. Sine waves are fundamentally different from dynamic music signals and therefore do not represent real audio signals very well [5], [6]. Real audio signals is much more dynamic and have a high peak-to-rms ratio, also known as the Crest Factor (CF). Fig. 1 shows the amplitude distribution of 183 audio tracks provided by [6].

It is observed that amplitude distribution between audio and sine waves are fundamentally different and that real audio signals in fact is much more dynamic compared to sine waves. This highly dynamic nature of audio signals causes a degradation of efficiency as less continuous output power can be achieved. The dominant losses in the amplifier at low output power are switching losses which directly relate to the supply voltage level. Low efficiency is a challenge as it indicates an excessive loss within the amplifier which can cause thermal stress on power stage components, increase the size of required heat sink and act as a limiting factor for play back time in battery driven systems.

A similar challenge exists for Radio Frequency (RF) power amplifiers where highly dynamic radio signals cause low efficiency [7]-[9]. To overcome this challenge within RF power amplifiers several methods have been proposed including Envelope Tracking (ET) and Envelope Elimination and Restoration (EER) [10]-[13]. This work aim to apply a multilevel level ET power supply to a $100 \mathrm{~W}$ class-D audio amplifier

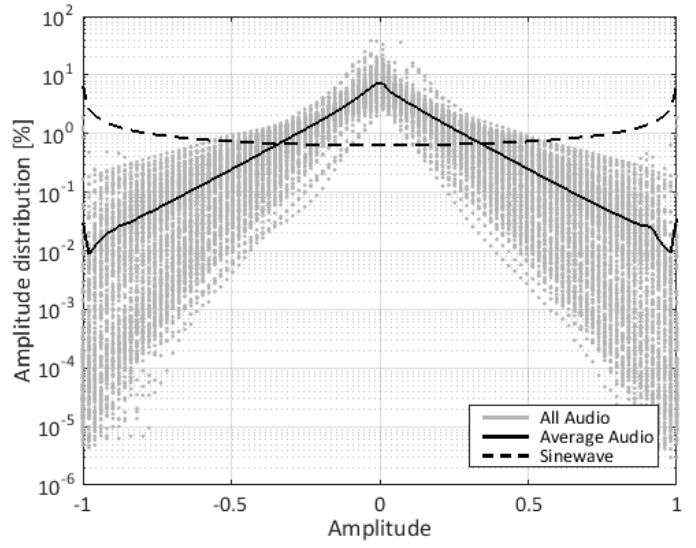

Fig. 1. Amplitude distribution of 183 audio tracks and sine wave [6].

in order to optimize efficiency and operating temperature when playing dynamic audio signals. This technique is not to be confused with conventionally class- $\mathrm{H}$ and class- $\mathrm{G}$ topologies as those are characterized by having a linear amplifier power stage, opposed to the switch-mode of class-D [14].

\section{Proposed Solution}

This section present the operating principle of the proposed ET power supply for the class-D amplifier along with relevant equations to estimate the expected impact on the system efficiency.

The core concept of the ET power supply is to supply the power amplifier with just the needed supply voltage so that the amplifier works correctly and does not produced excessive distortion due to clipping. For dynamics signals this will lower the switching losses significantly as they follow the simplified formula:

$$
P_{s w}=\frac{1}{2} C_{d s} V_{S}^{2} f_{s w}
$$

Where $C_{d s}$ is the parasitic capacitance of the amplifier switching device, $V_{S}$ is the supply voltage and $f_{s w}$ is the switching frequency. As seen from (1) the losses follows the supply voltage squared meaning that the magnitude of this voltage has great impact of the amount of switching losses. 


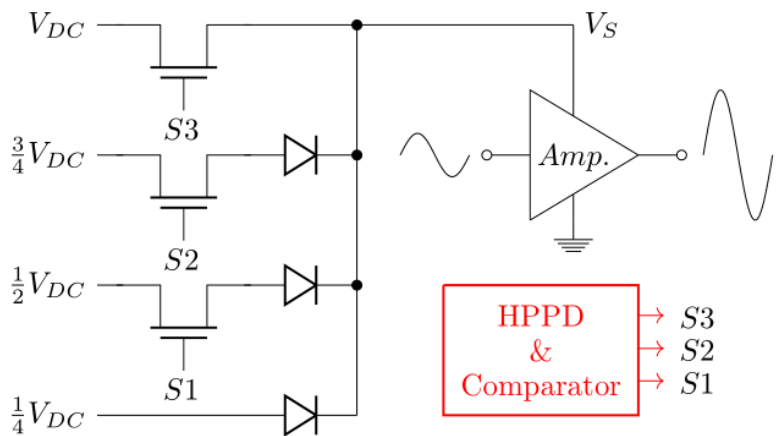

(a) Analog multiplexer.

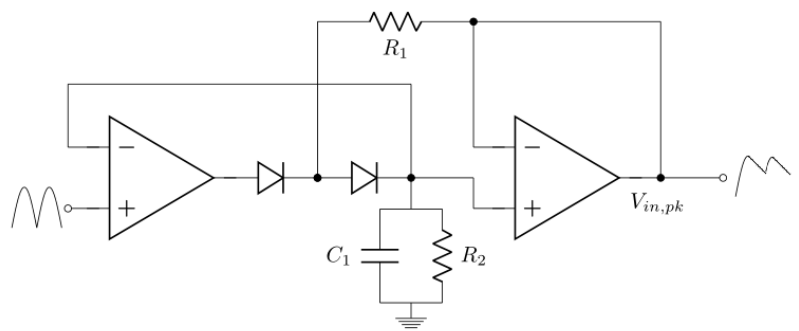

(b) HPPD circuit.

Fig. 2. Concept of proposed ET power supply consisting of a four level analog multiplexer and a High Precission Peak Detector (HPPD tracking circuit).

This paper proposes to implement the ET utilizing an analog multiplexer which selects the amplifier supply voltage, $V_{S}$ , from four evenly spaced predefined voltage levels. This selection is performed based on an analysis of amplitude of the audio input which ensures that the amplified audio output generated by the amplifier is never clipped to the supply voltage. Fig. 2(a) shows a simplified schematic of the analog multiplexer. The control signals, $S 1-S 3$, is generated from an analog High Precision Peak Detection (HPPD) circuit, shown in Fig. 2(b), which tracks the rectified audio input signal. The output of the HPPD, $V_{i n, p k}$, is fed to three comparators with hysteresis and individual thresholds, $v_{t h 1-3}$. The control signals, $S 1-3$, are enabled when the audio input triggers these thresholds:

$$
V_{i n, p k}>v_{t h 1-3}
$$

The speed of the tracking is set by the time constant formed by $C 1$ and $R 2$. The tracking speed does not need to very be fast to generate efficiency improvements as depicted in Fig. 3 which shows the predicted behaviour of the switching. Excessive switching in the multiplexer should be avoided as this will generate losses. Tracking speed is therefore a tradeoff and a variable that can be optimized in future work. The

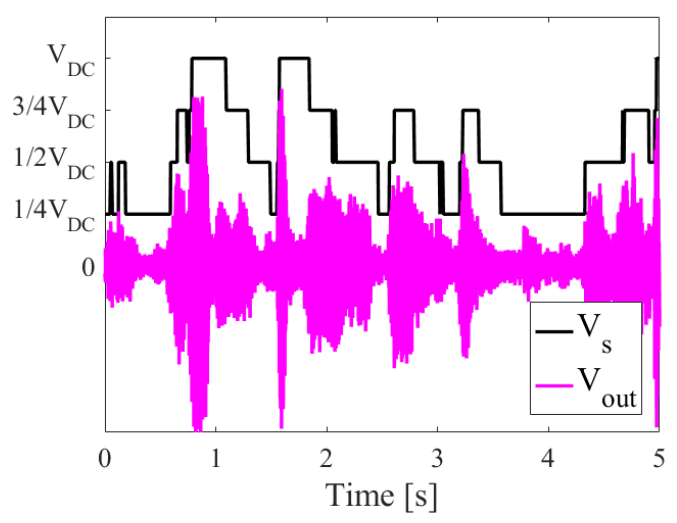

Fig. 3. Estimated Envelope Tracking (ET) power supply voltage, $V_{S}$, and amplifier output in case dynamic audio signal. impact on efficiency the proposed system can be theorised by using a loss model, $P_{\text {loss }}$, based on common equations for switch- and conduction-losses available from previous work [15], [16].

$$
P_{\text {loss }}=P_{\text {gate }}+P_{\text {cond }}+P_{\text {sw }}+P_{\text {reverse }}+P_{L f}
$$

Where $P_{\text {gate }}$ is gate-, $P_{\text {cond }}$ is conduction-, $P_{s w}$ is switching-, $P_{\text {reverse }}$ is reverse body diode conduction- and $P_{l f}$ is filterlosses. The loss model should be evaluated for all desired operating points and supply voltage levels so that it can be formalized as a two dimensional array.

$$
P_{\text {loss }}=\left(\begin{array}{cccc}
p_{1,1} & p_{1,2} & \cdots & p_{1, d} \\
p_{2,1} & p_{2,2} & \cdots & p_{2, d} \\
\vdots & \vdots & \ddots & \vdots \\
p_{n, 1} & p_{n, 2} & \cdots & p_{n, d}
\end{array}\right)
$$

where $n$ is the voltage level and $d$ is the operating point specifying a specific duty cycle. Equally the duty cycle distribution, $\phi$, of the amplifier power stage can be formalized as:

$$
\phi=\left(\begin{array}{cccc}
\phi_{1,1} & \phi_{1,2} & \cdots & \phi_{1, d} \\
\phi_{2,1} & \phi_{2,2} & \cdots & \phi_{2, d} \\
\vdots & \vdots & \ddots & \vdots \\
\phi_{n, 1} & \phi_{n, 2} & \cdots & \phi_{n, d}
\end{array}\right)
$$

The duty cycle distribution can be translated directly from the amplitude distribution of the audio signal, as long as the amplifier has a linear transfer function. The total loss can be described as the product between the loss model and the duty cycle distribution.

$$
P_{\text {tot }}=\sum_{n=1}^{N} \kappa_{n} \cdot \phi_{n} \cdot P_{\text {loss }, n}
$$

Where $N$ is the total number of supply voltage levels and $\kappa_{n}$ is an array containing the level distribution, i.e. the percentage spent on the $n$ 'th supply voltage level.

$$
\kappa=\left(\begin{array}{c}
\kappa_{1} \\
\kappa_{2} \\
\vdots \\
\kappa_{n}
\end{array}\right)
$$




\section{IMPLEMENTATION}

A prototype system was designed consisting of the ET power supply, equipped with analog multiplexer and the HPPD/comparator tracking circuit, and a $100 \mathrm{~W}$ switch-mode power amplifier, designed conventionally in accordance with [17]. Four fixed voltage levels was provided to the multiplexer circuit evenly spaced from 0 to $50 \mathrm{~V}$, i.e. $12.5 \mathrm{~V}, 25 \mathrm{~V}, 37.5 \mathrm{~V}$ and $50 \mathrm{~V}$. The time constant of the HPPD was set 12 seconds. The amplifier utilizes a synchronous buck topology in a full bridge configuration and has a gain of $32 \mathrm{~dB}$, i.e. $40 \mathrm{~V} / \mathrm{V}$. Fig. 4(a) shows the simplified schematic of the amplifier power stage. The input signal range of the amplifier is $+/-1 \mathrm{~V}$. The thresholds, $v_{t h 1-3}$, of the HPPD/comparator tracking circuit were set to $0.2 \mathrm{~V}, 0.4 \mathrm{~V}$ and $0.6 \mathrm{~V}$ respectively, meaning that the multiplexer provides $50 \mathrm{~V}$ when the input signal exceeds $+/-0.6 \mathrm{~V}$. These thresholds were selected to ensure some headroom to the supply voltage levels thus avoiding significant distortion on the amplified audio signal. Fig. 4(b) shows the implemented system.

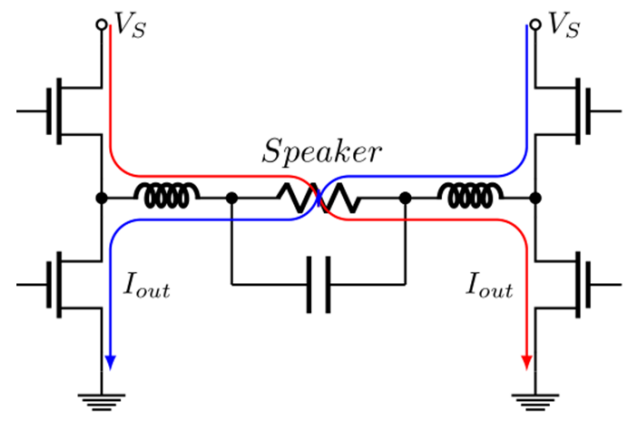

(a) Synchronous buck power stage.

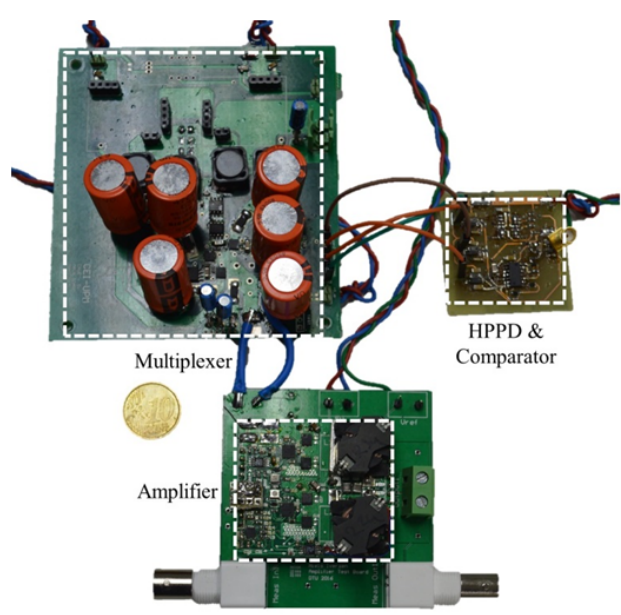

(b) Implemented system.

Fig. 4. Designed system consisting of audio amplifier using a synchronous buck topology and the proposed ET power supply consisting of analog multiplexer and HPPD/comparator tracking circuit.

\section{RESUlTS}

A series of measurements has been conducted in order to evaluate the impact on the system efficiency and its operating temperature. This includes measurements of system efficiency, using both conventional sine waves and dynamic audio signals

Fig. 7 shows the efficiency of the amplifier with and without the tracking power supply measured conventionally when driven by a sine wave. The input and output power is then measured using digital multi meters, Agilent 34401A. The measured efficiency is compared to predicted values obtained using (6). A good correlation between expectations and measurements is noticed. Especially for lower output powers. Moreover it is observed that the efficiency is greatly improved in the low power region when the tracking power supply is used. The low power efficiency is very important as the most probable power level lies in this range when playing real audio signals instead of sine waves. At $1 \mathrm{~W}$ the efficiency is improved from $30 \%$ to $65 \%$. For high output levels the efficiency of the system with tracking supply has slightly lower efficiency as the additional circuitry in tracking power supply implementation add some losses. In addition to that the calculated predictions overestimates the efficiency 5 to $7 \%$ at higher output powers. This can be explained as a consequence of inaccurate modelling since the loss model does not account for the temperature and voltage dependent nature of the parasitic components of the switching device, e.g parasitic capacitance and on-resistance.

In order to evaluate the efficiency performance using real audio, three audio tracks from different genres have been selected. They have different dynamics as their peak-to-rms ratio, aka. Crest Factor, varies from $8.9 \mathrm{~dB}$ to $20.4 \mathrm{~dB}$ as seen in Table I.

In order to ensure that the tracks are perceived equally loud they have been loudness normalized in accordance with the EBU- R128 recommendation [18], [19]. For measurement reasons only the first twenty seconds of each track have been considered. Five loudness levels have been selected going from low volume up to clipping, i.e. maximum power. The

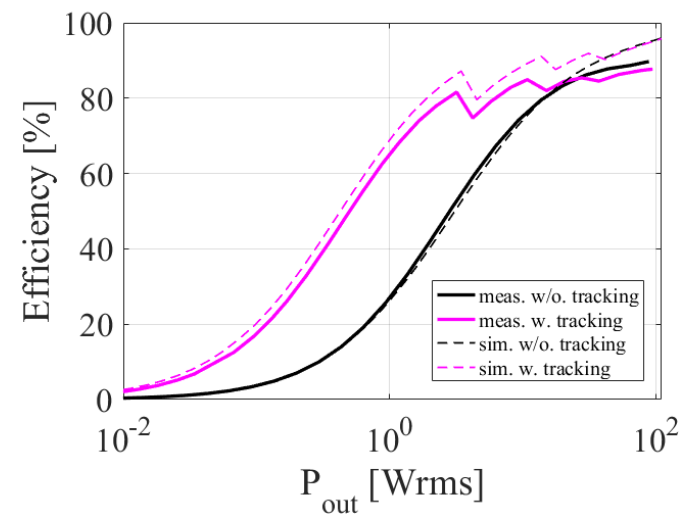

Fig. 5. Simulated and measured efficiencies with and without tracking. 
corresponding rms output power can be found in Table II. A DPO3014 oscilloscope from Tektronix equipped with high precision current and voltage probes was used to capture the highly dynamic input and output voltages/currents. With a record length of 10 million points this oscilloscope ensures a sufficient sampling frequency when considering a 20 second audio signal. Fig. 6 shows the measured supply voltage as well as amplifier output playing Daft Punk - Get Lucky at loudness level 5. Though the tracking speed is slow it is clear that the proposed method ensures that supply voltage is vastly lowered for the majority of the audio signal. This will inevitably lower the losses in the power stage. Fig. 7(a) shows the measured and simulated efficiency of each track for the different loudness levels. The simulated results are based on the expected losses obtained using (6). There is a good correlation between the measured and expected results. It is observed that for all tracks and loudness levels the efficiency of the designed system is improved when the tracking power supply is enabled. Especially for low loudness levels the efficiency were improved. That is from 2 to $5 \%$ without tracking to 12 to $20 \%$ with tracking across the different tracks, i.e. up to a factor 6 improvement. In terms of power losses they were cut down from $2.5 \mathrm{~W}$ to only $0.5 \mathrm{~W}$. The efficiency improvement is less significant for higher loudness levels but still a clear improvement is observed. That is from 32 to $53 \%$ without tracking to 59 to $76 \%$ with tracking across the different tracks. The highly dynamic jazz track, "Cant we be friends" marked by "o" in the figures, experiences the greatest efficiency improvement over all loudness levels. The influence of the tracking speed is also investigated. Fig. 7(b) shows the measured and simulated efficiency of the jazz track when the HPPD time constant is lowered from 12 to 3 seconds, resulting in a faster tracking. As expected the efficiency is increased for higher loudness levels but at the price of the signal quality as faster switching produces noise at the amplifier output.

The operating temperatures, in case of a 12 seconds HPPD time constant, were measured using a thermal camera. Fig.

TABLE I

CREST FACTORS OF SELECTED AUDIO TRACKS.

\begin{tabular}{|l|l|l|l|r|}
\hline & Name & Artist & Genre & $C F$ \\
\hline 1 & Can't We Be Friends & Ella \& Louis & Jazz & $20.4 \mathrm{~dB}$ \\
2 & Redneck & Lamb of God & Metal & $8.9 \mathrm{~dB}$ \\
3 & Get Lucky & Daft Punk & Pop & $13.0 \mathrm{~dB}$ \\
\hline
\end{tabular}

TABLE II

CORRESPONDING OUTPUT POWER FOR DIFFERENT LOUDNESS LEVELS.

\begin{tabular}{|l|c|c|c|c|c|}
\hline \multicolumn{7}{|c|}{ Loudness level vs. output power } \\
\hline Loudness level & 1 & 2 & 3 & 4 & 5 \\
\hline \multicolumn{7}{|c|}{ First 20 seconds } \\
\hline Ella \& Louis & $0.06 \mathrm{~W}$ & $0.20 \mathrm{~W}$ & $0.56 \mathrm{~W}$ & $0.80 \mathrm{~W}$ & $1.20 \mathrm{~W}$ \\
Lamb of God & $0.08 \mathrm{~W}$ & $0.25 \mathrm{~W}$ & $0.71 \mathrm{~W}$ & $1.00 \mathrm{~W}$ & $1.50 \mathrm{~W}$ \\
Daft Punk & $0.14 \mathrm{~W}$ & $0.47 \mathrm{~W}$ & $1.34 \mathrm{~W}$ & $1.90 \mathrm{~W}$ & $2.80 \mathrm{~W}$ \\
\hline \multicolumn{7}{|c|}{ Full track } \\
\hline Ella \& Louis & $0.10 \mathrm{~W}$ & $0.33 \mathrm{~W}$ & $0.93 \mathrm{~W}$ & $1.3 \mathrm{~W}$ & $1.96 \mathrm{~W}$ \\
Lamb of God & $0.14 \mathrm{~W}$ & $0.46 \mathrm{~W}$ & $1.32 \mathrm{~W}$ & $1.86 \mathrm{~W}$ & $2.77 \mathrm{~W}$ \\
Daft Punk & $0.18 \mathrm{~W}$ & $0.59 \mathrm{~W}$ & $1.69 \mathrm{~W}$ & $2.38 \mathrm{~W}$ & $3.56 \mathrm{~W}$ \\
\hline
\end{tabular}

8 shows the measured operating temperature of the audio amplifier with and without the tracking power supply in idle and for the selected audio tracks at loudness level 5. It is observed that in general the operating temperature is greatly reduced. Especially for the four switching MOSFETs

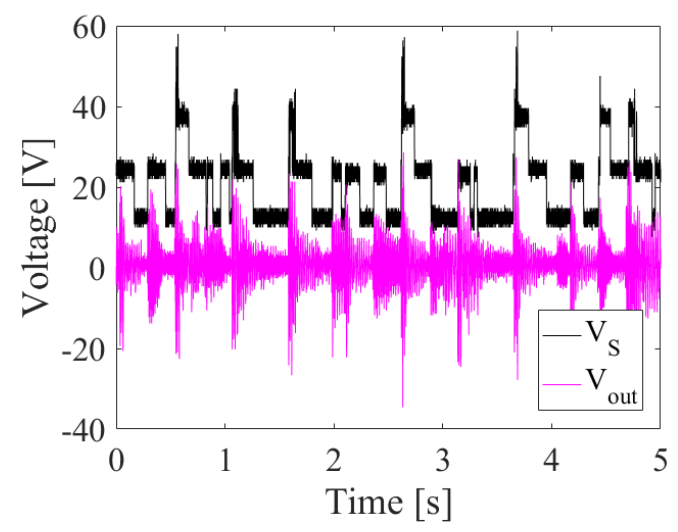

Fig. 6. Multilevel supply voltage and amplifier output in case of Daft Punk Get Lucky.

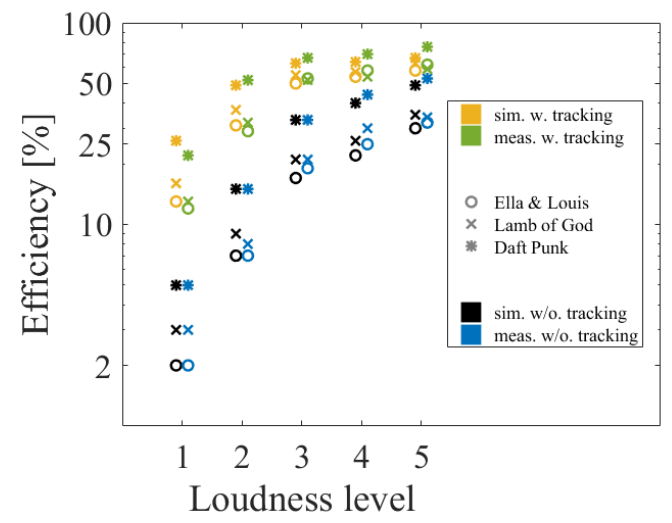

(a) Efficiency of implemented system.

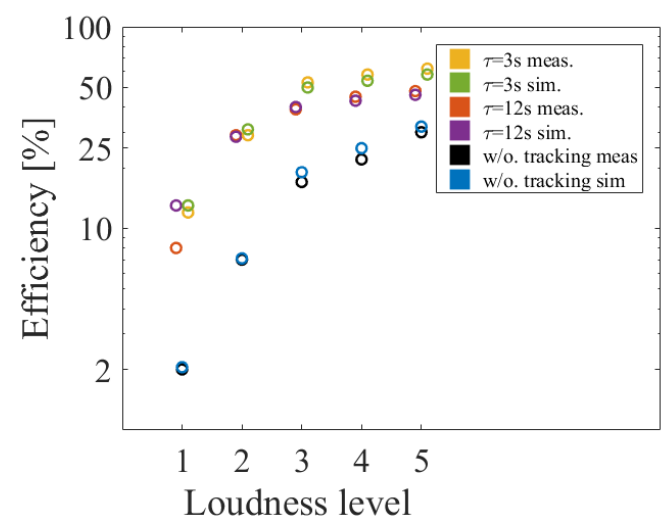

(b) Impact from faster tracking.

Fig. 7. Simulated and measured efficiencies for first 20 seconds of audio tracks. The corresponding output power for each track and loudness level is shown in Table II. 


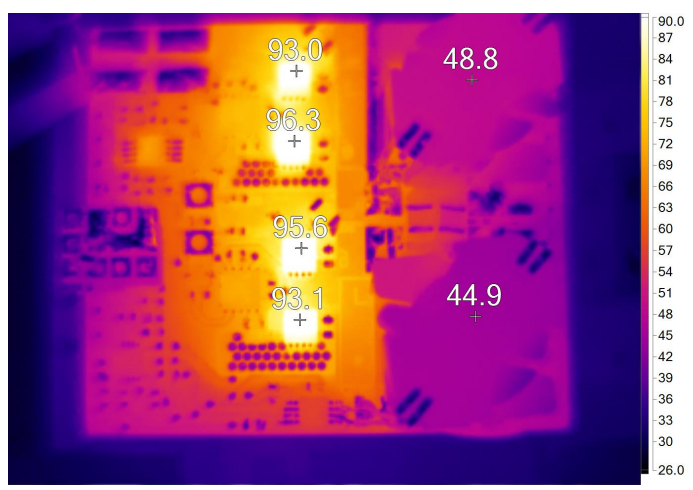

(a) Idle - Without tracking.

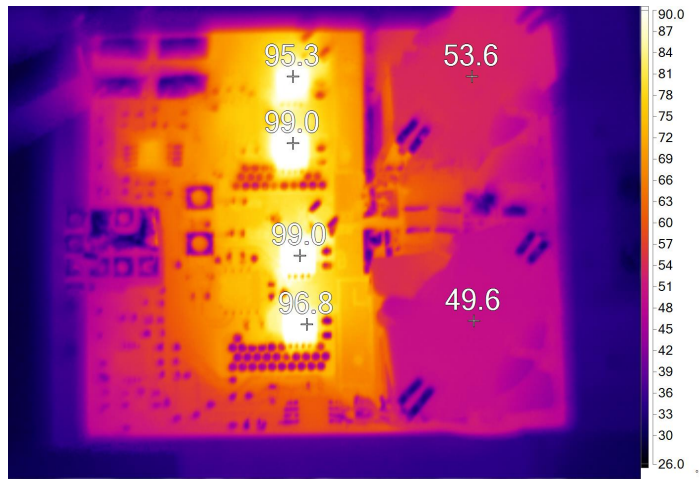

(c) Ella \& Louis - Without tracking.

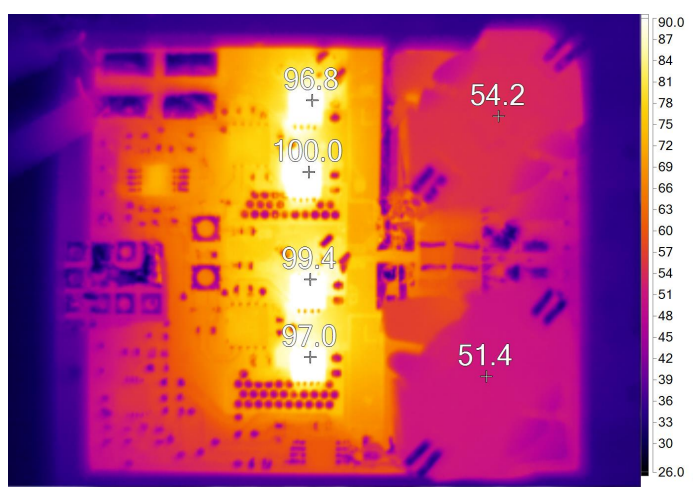

(e) Lamb of God - Without tracking.

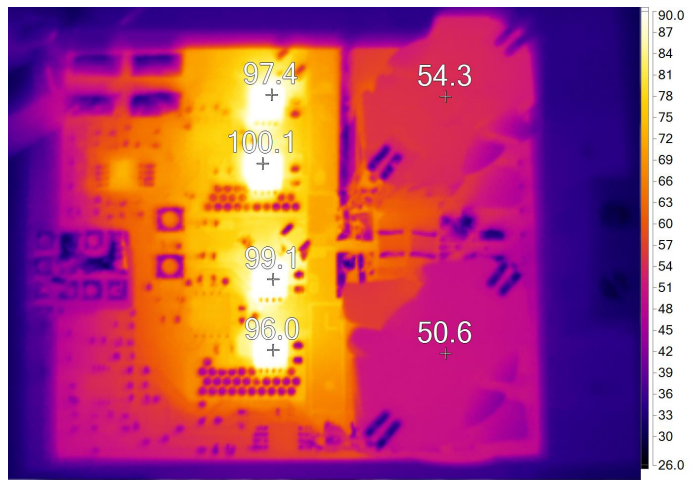

(g) Daft Punk - Without tracking.

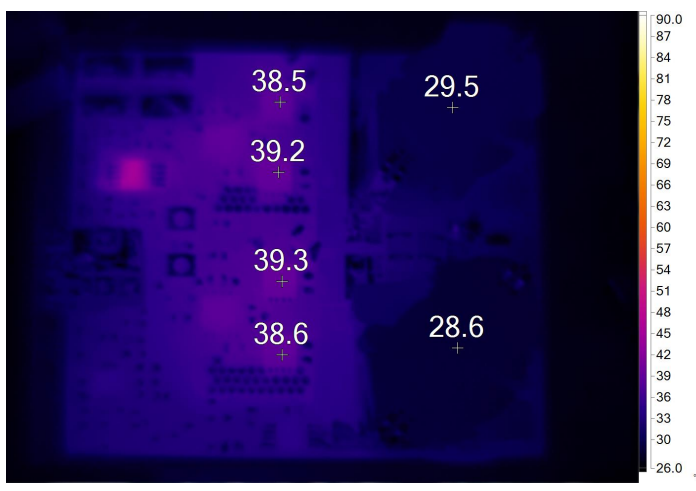

(b) Idle - With tracking.

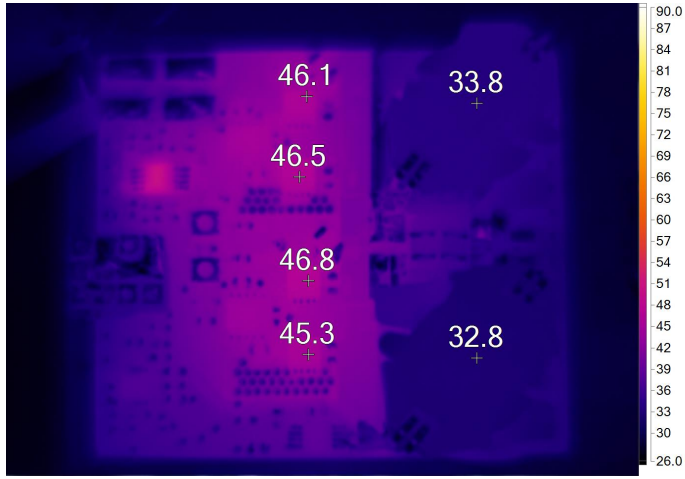

(d) Ella \& Louis - With tracking.

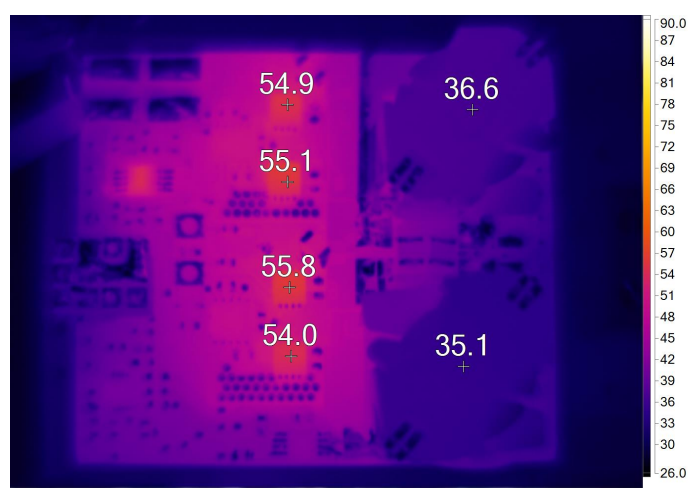

(f) Lamb of God - With tracking.

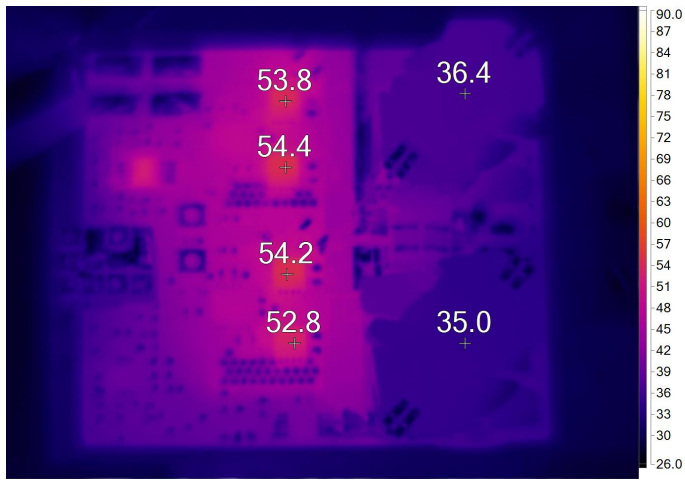

(h) Daft Punk - With tracking.

Fig. 8. Measured temperatures of amplifier with- and with-out tracking at loudness level 5. 
in the amplifier power stage where the temperature is halved from approximately $100{ }^{\circ} \mathrm{C}$ to $50{ }^{\circ} \mathrm{C}$ across all tracks. In the same manner the inductor temperature is reduced from approximately $50{ }^{\circ} \mathrm{C}$ to $35{ }^{\circ} \mathrm{C}$. A summary of the measured operating temperatures is presented in Table III. This great reduction in MOSFET operating temperature is obtained as the switching losses are greatly reduced. The reduction of the temperature in the filter inductor is related to a smaller ripple current when the supply voltage is low thus causing less AC winding- and core-losses.

Finally crude listening test where performed to evaluate audio quality when the tracking power supply is enabled. From these listening sessions it is clear that the level-shifting, introduced by the tracking power supply, generates undesired audible clicks and therefore it has a negative effect on the audio performance. This can be solve either by having a higher power supply rejection ratio in the amplifier or a lower slew rate in the analog multiplexer. It remains future work to overcome this challenge.

\section{CONCLUSION}

The work presented in this paper proposes that tracking power supplies can provide similar efficiency improvements when applied to switch-mode power audio amplifiers as shown for RF amplifiers in previous work. To demonstrate this hypothesis a prototype system was designed consisting of a $100 \mathrm{~W}$ power audio amplifier and a tracking power supply based on an analog multiplexer. Measured results show that systems using a tracking power supply achieve significantly higher efficiencies. Especially for low loudness levels the efficiency were improved up to a factor of 6 . That is from approximately 2 to $5 \%$ without tracking to 12 to $20 \%$ with tracking across different music genres. In terms of power losses they were cut down from approximately $2.5 \mathrm{~W}$ to only $0.5 \mathrm{~W}$. In addition to that it is observed that the amplifier operating temperature is strongly reduced, especially for the switching power MOSFETs where it has been halved from $100{ }^{\circ} \mathrm{C}$ to $50{ }^{\circ} \mathrm{C}$. Moreover measured results show that the efficiency can be further improved for high loudness levels, by increasing the tracking speed.

\section{FUTURE WORK}

Future work includes an implementation using a switch-cap circuit to generate the fixed voltage levels as proposed in [9]. In addition to this the control signals, $S 1-S 3$, may be implemented on an audio DSP instead of the HPPD/comparator

TABLE III

SUMMARY OF TEMPERATURE MEASUREMENTS SHOWN IN FIG. 8

\begin{tabular}{|l|c|c|c|c|}
\hline \multicolumn{4}{|c|}{ Mean temperatures } \\
\hline & \multicolumn{2}{|c|}{ w/o. tracking } & \multicolumn{2}{c|}{ w. tracking } \\
\hline Input & MOSFETs & Ind. & MOSFETs & Ind. \\
\hline Idle & $94.5 \mathrm{C}^{\circ}$ & $46.9 \mathrm{C}^{\circ}$ & $37.2 \mathrm{C}^{\circ}$ & $29.1 \mathrm{C}^{\circ}$ \\
Ella \& Louis & $97.5 \mathrm{C}^{\circ}$ & $51.6 \mathrm{C}^{\circ}$ & $46.2 \mathrm{C}^{\circ}$ & $33.3 \mathrm{C}^{\circ}$ \\
Lamb of God & $98.3 \mathrm{C}^{\circ}$ & $52.8 \mathrm{C}^{\circ}$ & $55.0 \mathrm{C}^{\circ}$ & $35.9 \mathrm{C}^{\circ}$ \\
Daft Punk & $98.2 \mathrm{C}^{\circ}$ & $52.5 \mathrm{C}^{\circ}$ & $53.8 \mathrm{C}^{\circ}$ & $35.7 \mathrm{C}^{\circ}$ \\
\hline
\end{tabular}

circuit, as audio DSPs is a typical component in audio systems [21]. Finally good audio quality must be ensured. That means no audible artefacts on the amplified audio signal. This can be achieved either by having high power supply rejection ratio in the amplifier or a lower slew rate in the analog multiplexer, meaning that the jump in supply voltage level happens slower.

\section{REFERENCES}

[1] B. Putzeys, "Simple Self-Oscillating Class D Amplifier with Full Output Filter Control", in 118th Audio Engineering Society convention, Barcelona, May 28-31, 2005.

[2] S. Poulsen, M.A. Andersen, "Simple PWM modulator topology with excellent dynamic behavior", in IEEE APEC, 2004.

[3] M. C. W. Hyerby and M. A. E. Andersen, "Carrier Distortion in Hysteretic Self-Oscillating Class-D Audio Power Amplifiers: Analysis and Optimization”, IEEE Transactions on Power Electronics, 2009.

[4] K. Nielsen, "Audio Power Amplifier Techniques With Energy Efficient Power Conversion", Ph.D. thesis, Volume 1, Technical University of Denmark 1998

[5] R. A. R. van der Zee and A. J. M. van Tuijl, "Test Signals for Measuring the Efficiency of Audio Amplifiers", in 102nd Audio Engineering Society convention, Amsterdam, May 16-19, 1998.

[6] N. E. Iversen, A. Knott and M. A. E. Andersen, "Efficiency of SwitchMode Power Audio Amplifiers - Test Signals and Measurement Techniques", in 140th Audio Engineering Society convention, Paris, 4-7 June, 2016.

[7] Q. Jin, M. Vasic, O. Garcia, P. Alou and J. A. Cobos, "Optimized design of Gan switching capacitor based envelope tracking power supply for satellite applications", in APEC 2016. DOI: 10.1109/APEC.2016.7468203.

[8] M. Vasic, O. Garcia, J. A. Oliver, P. Alou, D. Diaz and J. A. Cobos, "Envelope amplifier based on switching capacitors for high-efficiency RF amplifiers", IEEE Trans. Power Electronics, vol. 27, no. 3, pp. 1359-1368, March 2012. DOI: 10.1109/TPEL.2011.2163646.

[9] V. Lazarevic, M. Vasic, O. Garcia, Q. Jin, P. Alou, J. A. Oliver and J. A. Cobos, "A comparative analysis of two approaches in EER based envelope tracking power supplies", in APEC 2017. DOI: 10.1109/APEC.2017.7931163

[10] Z. Wang, Envelope tracking power amplifiers for wireless communications, Artech House, Boston, 2014.

[11] M. Vasic, O. Garcia, J. A. Oliver, P. Alou, D. Diaz and J. A. Cobos, "Multilevel power supply for high-efficiency RF amplifier", IEEE Trans. Power Electronics, vol. 25, no. 4, pp. 1078-1089, April 2010. DOI: 10.1109/TPEL.2009.2033186.

[12] V. yousefzadeh, E. Alarcon and D. Maksimovic, "Three-level buck converter for envelope tracking applications", IEEE Trans. Power Electronics, vol. 21, no. 2, pp. 549-552, March 2006. DOI: 10.1109/TPEL.2005.869728.

[13] Leonard R. Kahn, Single-Sideband Transmission by Envelope Elimination and Restoration, Proceedings of IRE, vol. 40, no. 7, pp. 803-806, 1952. DOI: $10.1109 /$ JRPROC.1952.273844.

[14] J. Angus, "Ultra efficienct linear amplifiers", in 142nd Audio Engineering Society convention, Berlin, May 20-23, 2017.

[15] N. E. Iversen, N. J. Dahl, A. Knot. M. A. E. Andersen, Towards high power density audio amplifiers, submitted to IEEE Trans. Consumer Electronics, October 2017.

[16] Erickson and Maksimovic, Fundamentals of Power Electronics, Second Edition, Kluwer Academic Publishers.

[17] Application Report, "Design Considerations for Class-D Audio Power Amplifiers", Texas Instruments, 1999.

[18] EBU Technical Recommendation R 128: Loudness normalisation and permitted maximum level of audio signals.

[19] EBU Tech Doc 3343: Practical Guidelines for Production and Implementation in accordance with EBU Technical Recommendation R 128.

[20] EBU Tech Doc 3343: Practical Guidelines for Production and Implementation in accordance with EBU Technical Recommendation R 128.

[21] F. Rumsey, "DSP in Loudspeakers", in J. Audio Eng. Soc., vol. 56, no. 1/2, pp. 65-72, January 2008. 